\title{
REVIEW
}

\section{Application of New Materials in Contemporary Landscape Design}

\author{
Ke-Jia Shi* \\ Department of Architecture, School of Architecture Engineering, Zhejiang University of Technology, Hangzhou, Zhejiang, \\ China.
}

Corresponding Author: Ke-Jia Shi, Department of Architecture, School of Architecture and Engineering, Zhejiang University of Technology, No.18 Chaowang Road, Hangzhou 310014, Zhejiang, China. E-mail: kjs@163.com

\footnotetext{
Abstract

Throughout history, people's pursuit of "beauty" has never stopped. From the natural beauty of the past to all kinds of novel beauty, the new generation of landscape architects have tried many new design techniques and new applications. As a result, the development of new materials and technologies has received increasing attention. The new material is an indispensable and important factor in landscape design. It witnessed the urban development process and appeared more frequently with a new face. This study mainly explains the impact of different materials on the development of different eras, introduces the current status of new materials, summarizes the characteristics of new materials, and summarizes the ways in which new materials are used in contemporary landscapes. Finally, the future development trend of the new materials is prospected. It is hoped that this research will provide some suggestions for the current domestic landscape design practice to a certain extent, and build a bridge between design theory and practice.

Keywords

New materials for construction; contemporary greening; landscape design; low carbon and environmental protection
}

\section{INTRODUCTION}

"Material" is an indispensable element in the landscape, and it is the material carrier of the landscape ${ }^{[1]}$. Regardless of whether it is a western country or an eastern country, from the farming society to the modern society, the use of materials in landscapes has always been colorful ${ }^{[2]}$. Most of the early materials were natural materials that had not been carved and processed. They did not change the original appearance of the material too much, and focused on the combination of materials to create the atmosphere of Chinese classical gardens ${ }^{[3]}$. However, modern materials pay attention to their own properties, and have higher requirements for their technical synthesis and construction technology.

With the sustained and rapid development of China's economy, the modernization level of cities is getting higher and higher, and the proportion of greening in parks and squares in cities is becoming larger and larger ${ }^{[4]}$. There are all kinds of materials used in urban landscape. Materials are witnesses of the development of urban landscape in the past two centuries. As a key element of directly participating in modern landscape design, materials can represent the salient features of each

(C) The Author(s) 2019. Open Access This article is under the terms of Creative Commons Attribution 4.0 International License (https://creativecommons.org/licenses/by/4.0/), which permits unrestricted use, sharing, adaptation, distribution and reproduction in any medium or format, as long as you give appropriate credit to the original author(s) and the source, provide a link to the Creative Commons license, and indicate if changes were made. 
historical stage. The choice and use of materials at each period must highlight the atmosphere of the times ${ }^{[5-8]}$. The development of materials itself is also an important factor to promote urban modernization. Especially in the 21 st century, where the rapid development of science, technology and economic strength, the continuous development and progress of new materials can not only provide designers with new resources in the field of materials, but also bring new sensory experiences to users. Therefore, the choice of materials in the landscape must present the characteristics of the era of "innovation".

\section{CLASSIFICATION OF NEW MATERIALS IN CONTEMPORARY LANDSCAPE DESIGN}

\subsection{Constructing New Materials}

\subsubsection{Metal}

At first, metal materials were widely used in architectural design, and they were introduced into the scope of landscape design materials selection later. It is mainly used in landscape walls, structures and sketches. Metal gives the site users a strong sense of modernity, industry and fashion. In recent years, metal materials such as stainless-steel plates and weather-resistant steel plates have been applied in landscape design ${ }^{[9]}$. These new metal materials give people a high-cold temperament, but they give the landscape a modern feel. Stainless steel plate has polishing (mirror surface), wire drawing, and reticulation processing methods, which can be applied to various parts of the landscape.

The weathering steel plate is a steel alloy with a dense corrosion layer, which can achieve the natural rust effect of the steel plate and form a special artistic effect. It is often used in landscape walls, sculptures, characteristic sketches, etc., and reflects the modern industrial sense ${ }^{[10]}$. After ordinary steel is rusted, it will gradually age and corrode. At this time, the emergence of weathering resistant steel gives designers the opportunity to express their creative ideas. Designers can make full use of the rusted form to create. Weathering resistant steel has strong corrosion resistance. Under different natural environments, the process of forming a rust layer will also vary depending on the climate, location and direction.

\subsubsection{Concrete}

Contemporary concrete is the best choice of materials whether in the building or the landscape, but the concrete produced by high-tech is mainly permeable concrete and translucent concrete ${ }^{[11]}$. The high-quality performance of pervious concrete is reflected in that it can make rainwater quickly penetrate into the surface, reduce the load of drainage facilities, prevent road area water, reduce rainwater to groundwater, timely supplement groundwater resources, keep the soil moist, and make surface plants and soil microorganisms grow better in the city. At present, the permeability of most permeable concrete on the market is only 8.3 $\mathrm{L} / \mathrm{min} / \mathrm{m}^{2}$, while the permeability of Topmix concrete can reach $1000 \mathrm{~L} / \mathrm{min} / \mathrm{m}^{2}$, and the water absorption in one minute can reach $4000 \mathrm{~L}, 120$ times of the former. Unlike most concrete, Topmix concrete is not made of sand and stone as aggregate. Instead, small granite gravel is first put together at the bottom, leaving enough space for water supply to form gravel layer with strong surface penetration ${ }^{[12]}$. Then, in the middle, there are pebble aquifers, relatively soft rubble bottom and underground drainage pipes. This new concrete not only brings benefits to the pavement, but also brings different visual effects to the landscape. For example, in the design of waterscape, this concrete can be used to design different scenes, as shown in Figure 1.

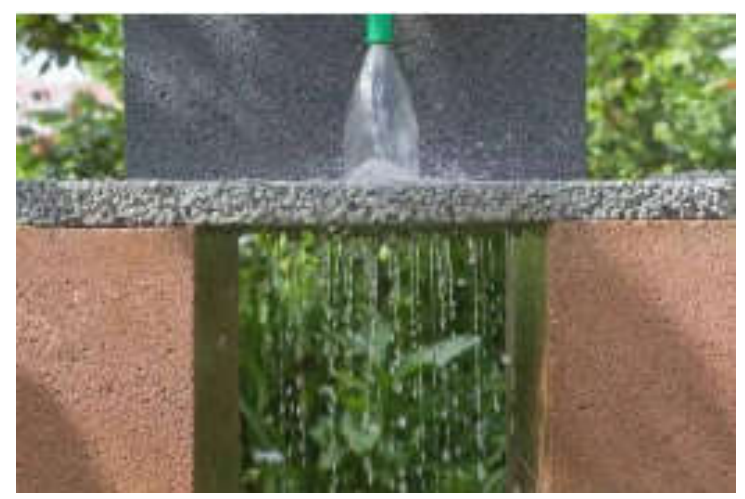

Figure 1 Application of permeable concrete in landscape

\subsubsection{Porcelain}

China is the hometown of porcelain. Traditionally, porcelain is mostly for decoration and appreciation to highlight the 
elegant quality of life. Because it is delicate and particularly easy to break, few designers move it out of the room. Its crystal beauty is often ignored. However, in recent years, designers have combined porcelain with other materials and produced unexpected results. The "Across the Abyss" art installation at London Design Week 2015 is made of ceramic tiles and transparent acrylic plates. It uses art tile technology to print pre-customized colors on the tiles so that the color of one tile behind is greater than the other. The color is $3 \%$ lighter, so that these tiles are placed next to each other, showing a gradient effect. The color of each transparent acrylic plate will also create a subtle with different contours and shadows ${ }^{[13]}$. For the first time, the "ceramic cloud" (Figure 2) designed by an Italian designer used ceramics as a structural material. A large piece of sacrificial porcelain plate was mechanically processed and specially designed and connected with metal parts to form ceramic elements.

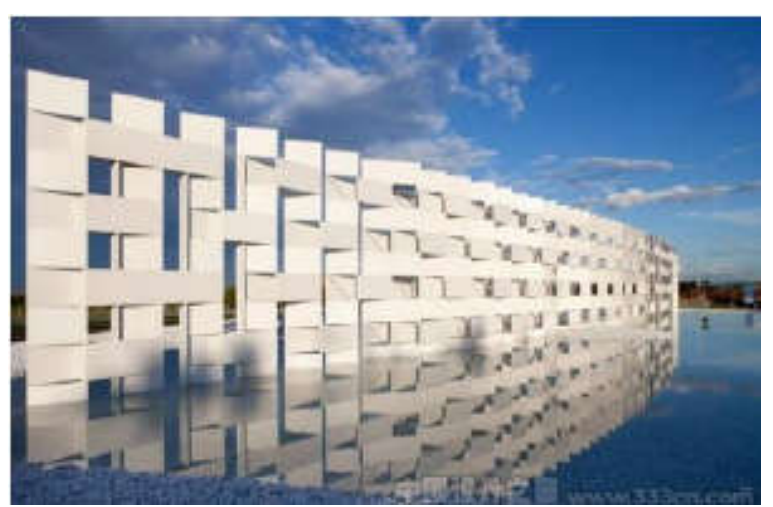

Figure 2 "Ceramic cloud" art device

\subsection{Paving New Materials}

\subsubsection{Self-cleaning Permeable Brick}

Permeable and permeable brick is superior to other pavement materials. It has shown good ecological benefits and is becoming more and more popular in cities ${ }^{[14]}$. Its advantages are mainly reflected in protecting the groundwater resources, improving the surface soil environment, optimizing the environment of light and sound in the city, reducing the phenomenon of "heat island effect" in the city and purifying water bodies, which is beneficial to urban fishing. In addition, it can also fill the deficiencies brought by hard roads.

There are many types of permeable bricks, including ordinary permeable bricks, concrete permeable bricks, colored stone composite concrete permeable bricks, ecological sand-based permeable bricks, and self-cleaning permeable bricks. Among them, the self-cleaning permeable brick is a new type of material in the permeable brick. It has been improved on the basis of the Dutch brick, so that it not only retains the characteristics of the Dutch brick's diverse colors, wear resistance and non-slip, but also has the function of breathable water. It can absorb surface water and penetrate water underground, fully replenish the scarce urban groundwater resources, and alleviate the waterlogging caused by road runoff to some extent. The self-cleaning permeable brick is like a permeable suit covering the road. When it rains, the rain water seeps into the ground quickly. When the sun comes out, the water stored in the brick evaporates to balance the surface temperature. The compressive strength of self-cleaning permeable brick is $40 \mathrm{MPa}$, which is twice that of ordinary permeable brick. There are three main specifications of self-cleaning permeable brick on the market at present. Their length and width are $200 \mathrm{~mm} \times 100 \mathrm{~mm}$. There are some differences in thickness, and their thicknesses are $60 \mathrm{~mm}, 50 \mathrm{~mm}$ and $80 \mathrm{~mm}$ respectively. Their porosity is about $20 \%$, permeability is $5 \mathrm{~mm} / \mathrm{s}$, and waterretaining property is $12 \mathrm{~L} / \mathrm{m}^{2}$. Even in rainy days, its anti-slip value can reach above 60 BPN. Some researchers once performed experiments with self-cleaning permeable bricks. Clearing stickers from the ground is the most difficult job for sanitation workers. However, the sticker on the self-cleaning permeable brick will fall off naturally after two weeks. In order to make the self-cleaning permeable brick impervious to water, some people even intentionally put it in the engine oil for soaking, and then put it in the sun for one week. As a result, the pores of the self-cleaning permeable brick open naturally, and the permeable function of the self-cleaning permeable brick is opened automatically.

\subsubsection{PC Imitation Stone Brick}

PC means "prefabricated concrete", and PC imitation stone brick is simply a new material that looks like stone in 
appearance, but it is essentially a new type of ceramic tile. it has been gradually used in landscape design and has become a new material for landscape. PC imitation stone brick is beautiful and practical. It not only has the natural and gorgeous appearance of stone, but also has the color and permeability of ordinary colored floor tiles. Not only that, it is extremely cost-effective, and the price is only half of the same quality stone. PC imitation stone brick uses natural stone color to avoid the possibility of fading, and it can also protect the environment and reduce the pressure of scarce resources, because it is made from waste resources $^{[15]}$. The strength grade of PC imitation stone brick is $\mathrm{C} 40$, the compressive strength is about $30-50 \mathrm{MPa}$, and the performance is equivalent to $110 \%$ of the stone. The flexural strength is about $10.2 \mathrm{MPa}$, which is higher than $10 \%$ of the stone. The wear resistance can reach 5.2. It is much higher than all kinds of pavement materials, and has good anti-slip property. The swing value is BPN 60-80. The ratio of PC imitation stone brick to ordinary granite floor tile is 60:32, which is almost double. The property will be higher. PC imitation stone brick has a certain water permeability, but it is not the best, and the water permeability is $5.0 \%$.

Table 1 Comparison of performance of PC imitation brick and stone and permeable brick

\begin{tabular}{|c|c|c|c|}
\hline Item & PC imitation stone brick & Permeable brick & Natural stone \\
\hline Crush strength & $30-50 \mathrm{MPa}$ & 20-50 MPa & $20-50 \mathrm{MPa}$ \\
\hline Landscape effect & beautiful, imitation stone effect & average effect & beautiful and textured \\
\hline Comprehensive cost & medium & low & high \\
\hline Color stability & real stone product, does not fade & Long time, colors fade & do not fade \\
\hline Construction performance & $\begin{array}{l}\text { easy to cut on-site construction, strong } \\
\text { size diversity }\end{array}$ & not easy to cut & not easy to cut \\
\hline Chromatic aberration & $\begin{array}{l}\text { controllable (multiple batches can be } \\
\text { controlled in a consistent manner) }\end{array}$ & $\begin{array}{l}\text { controllable (multiple batches can be } \\
\text { controlled in a consistent manner) }\end{array}$ & difficult to control \\
\hline Abrasion resistance & 5.2 & 3.5 & 4.4 \\
\hline Specifications & simple mold and rich size & simple mold and rich size & regular specifications, limited variety \\
\hline Water permeability & impermeable & permeable & impermeable \\
\hline
\end{tabular}

Note: PC: prefabricated concrete.

It can be seen from Table 1 that, in terms of cost, permeable bricks are the cheapest, natural stone is the most expensive, and PC imitation stone bricks are average. In terms of aesthetic value, PC imitation stone bricks and natural stone are both ideal, and permeable bricks are average. In terms of rate, permeable bricks undoubtedly have the best water permeability. The natural stone and PC imitation stone bricks are generally not good. Therefore, through comprehensive comparison, PC imitation stone bricks are reasonable in cost and ideal in visual effects. In landscape design, PC imitation stone bricks can be used for paving roads in landscape gardens and parks, as well as the construction of landscape sketches. It is colorful with texture, and has a high aesthetic value. The construction of PC stone-like bricks is relatively simple. First, the plain soil is compacted, and 5-25 graded crushed stones (about $15 \mathrm{~cm}$ ) on plain soil is spread. Then, C25 concrete (about 10-15 cm) is put on the grade. With crushed stones, 1: 4 cement mortar (about $30 \mathrm{~mm}$ ) is spread on the concrete. If the road requires heavy loads, the cement (about 1-2 $\mathrm{mm}$ ) is grouted. Finally, according to the design pattern requirements, PC imitation stone bricks were laid.

\subsubsection{Wood Plastic Composite}

Wood-plastic composite materials are new materials that combine wood fibers with thermoplastic resins or other materials, of which wood fibers account for a large proportion. In order to make up for the lack of solid wood materials, it can add wood fibers to $75 \%-80 \%$. Wood-plastic composite materials containing fibers are mixed with plastics to make them have better elasticity, greatly reduce cracking and corrosion, and reduce the burden of later maintenance. The wood-plastic composite material has B1 level fire resistance. When a flame ignites, it will go out automatically. Wood plastic composite has a 50-year life. In addition, it is of great significance to ecological environment protection. Waste wood-plastic composite materials can be recycled to $100 \%$ of wood-plastic raw materials, and then extruded and used in the site, which are environmentally friendly new materials.

The composition of wood-plastic composite materials not only has the water-resistant and anti-corrosion function of 
plastics, but also the natural texture of wood. At present, there are two kinds of wood-plastic materials in China: polyethylene (PE) wood-plastic and polyvinyl chloride (PVC) wood-plastic. PE is mostly used in garden landscapes and architectures, such as ground paving in garden landscapes, the design of outdoor tables and chairs, stair railings, hydrophilic platforms, etc. (Figure 3). Wood-plastic composites have many colors to choose from and are highly malleable, which is conducive to creating a space of vitality and natural ecology in the landscape. It is one of the more popular materials in contemporary landscapes.

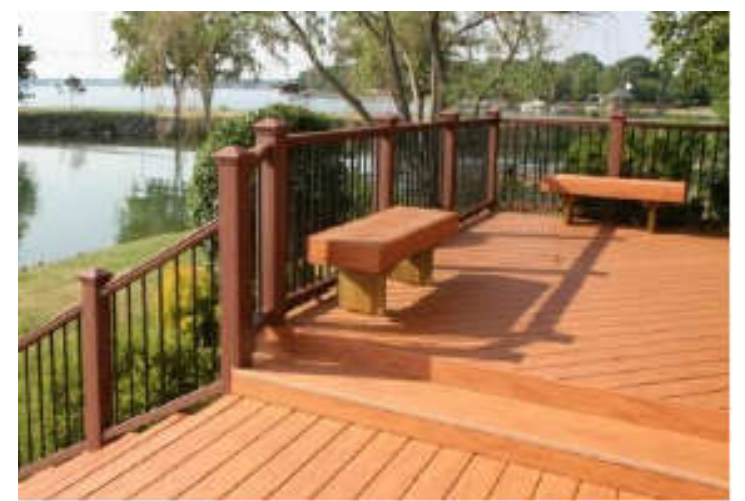

Figure 3 The application of wood - plastic composite material in landscape

\subsection{New Lighting Materials}

\subsubsection{Light Emitting Diode (LED)}

LED is a kind of diode cold light source with extremely high electro-optical conversion efficiency. The conversion rate is $60 \%$. It not only has low working voltage, energy saving and environmental protection, but also has a longer service life than other light sources (Table 2). Because its exterior is sealed with epoxy resin, the inside of the lamp will not be loose, fragile and easy to burn the filament. It also has good shock resistance and impact resistance. In addition, it can illuminate a dazzling point light source to create a vibrant space at night. In landscapes, LEDs are often used as contour lights, lawn lights, floor lights, beam lights, etc. Its products are: LED neon lights, neon lights are bright in color and strong in shape. LED decorative lights can be used in a variety of places and small pieces, with high color purity and high brightness. LED ball lights are mostly used for decorative effects in lawns (Figure 4).

Table 2 Comparison between LED lights and other light sources

\begin{tabular}{ccccccc}
\hline & Luminous efficiency & Service life & Display property & Startup characteristics & Restart time & $\begin{array}{c}\text { Does frequent } \\
\text { switching affect life }\end{array}$ \\
\hline LED & $110-170 \mathrm{Lm} / \mathrm{W}$ & $60,000-100,000 \mathrm{~h}$ & $70-95$ & fast & fast & no \\
Incandescent & $12-24 \mathrm{Lm} / \mathrm{W}$ & $1000 \mathrm{~h}$ & 60 & moment & moment & yes \\
Fluorescent lamp & $50-120 \mathrm{Lm} / \mathrm{W}$ & $2000 \mathrm{~h}$ & 70 & $3 \mathrm{~s}$ & $3 \mathrm{~s}$ & yes \\
Metal halide lamp & $55-110 \mathrm{Lm} / \mathrm{W}$ & $5000-20,000 \mathrm{~h}$ & $70-80$ & $3 \mathrm{~m}$ & $10-30 \mathrm{~m}$ & yes \\
Electrodeless lamp & $50 \mathrm{Lm} / \mathrm{W}$ & $60,000 \mathrm{~h}$ & $\leq 80$ & moment & moment & no \\
\hline
\end{tabular}

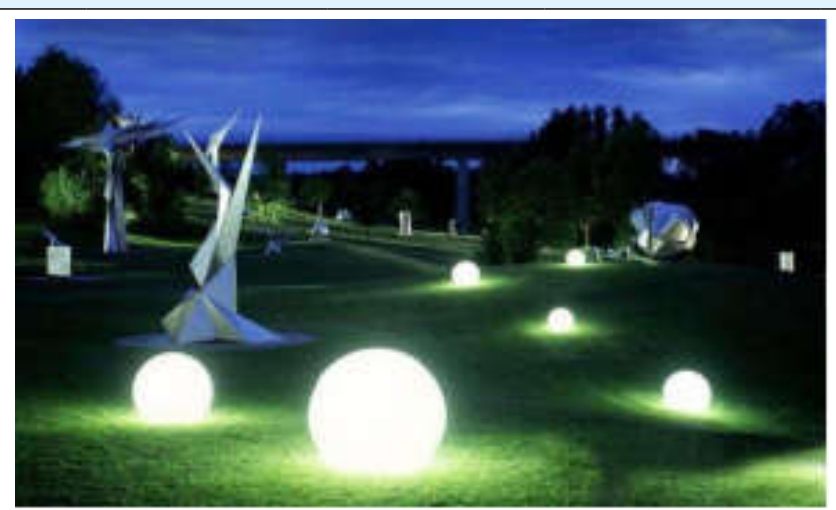

Figure 4 LED ball lights 


\subsubsection{Laser Lighting}

Laser lighting is a new type of lighting material with high brightness, low energy consumption, and accurate light type. It can be quickly and safely controlled by a calculator to bring dynamic lighting effects and strong visual impact. Shuji Nakamura had predicted that in the future, laser lighting might replace LEDs and become the mainstream of lighting. However, due to the high brightness and clear direction of the laser illumination, improper use will damage eyes, and during use, the laser source should be swung uniformly to ensure the safety and authenticity of the irradiated items. In the landscape, laser lighting often exists as a decoration, which can be used with waterscapes and plants. It has a strong sense of direction. Multiple lasers interlaced lighting can create special artistic effects ${ }^{[16]}$. If it is programmed by a calculator program, it can also create a fantastic water screen movie.

\subsubsection{Solar Lighting}

Solar light is a new type of pollution-free lighting material. It converts sunlight and wind power into electricity. The energy saving rate is $100 \%$. It is a one-time energy source and a renewable energy source without the need to add any fuel. It can be used in any area. For remote areas with poor conditions in all aspects, it can use solar power to design a more energy-efficient lighting power generation system for the local terrain and surrounding buildings and landscapes. Solar lighting can work in the environment of $-40{ }^{\circ} \mathrm{C}$ to $50{ }^{\circ} \mathrm{C}$. During the installation, the loss of natural factors such as thunder, rain, and snow must be considered. Some safety protection measures should be taken, and the service life of the light source and electrical components should be taken into account under the specific temperature. When the solar lighting battery is fully charged, the voltage is $14.7 \mathrm{~V}$, which is about $10.7 \mathrm{~V}$ when discharged, and about $10 \mathrm{~V}$ when it is rainy.

In specific applications, solar energy can provide traditional lamps, store energy, and release it when it is needed. It can also provide dreamy luminous road effects, such as the "smart road" in the Netherlands. Designers use Glowing Lines luminous paint materials to create the world's first safe and intelligent road that can emit light. These luminous paints automatically absorb daylight during the day, and provide about 10 hours of lighting at night. The road is also covered with "dynamic paint", which allows it to withstand temperatures of $23-69^{\circ} \mathrm{F}$. In 2013, Cambridge, England, designed and invented the solar-powered star path road lighting. The pavement is waterproof and non-slip, and absorbs sunlight during the day and releases light at night. Idaho in the United States has developed a section of solar-powered roads. They installed solar panels and light-emitting diodes below the road surface to light up road signs on overcast days and nights. These solar panels are also covered with mosaic-like lights. At night, they remind people like traffic signs and warning messages.

\subsection{Greening New Materials}

\subsubsection{Reinforced Water Storage and Drainage Board}

Water storage and drainage boards have been used for roof greening in earlier years. Because the concept of a sponge city has not been emphasized in the past, the water storage and drainage boards in the past did not have sufficient water storage capacity. However, the enhanced water storage and drainage boards increase the thickness to $80 \mathrm{~mm}$, which makes its water storage capacity significantly improved. Water storage and drainage boards are mainly divided into grid interlaced type and uneven type. The concave-convex type water storage and drainage plate is more popular in the market because of its lower price and strong water storage capacity. The concave-convex type water storage and drainage board is divided into two types, hollow and non-hollow, with a length of $500 \mathrm{~mm}$ and a width of only $500 \mathrm{~mm}$, which differ only in thickness: $20 \mathrm{~mm}, 25 \mathrm{~mm}$, and 30 $\mathrm{mm}$. The non-hollowed one has the function of blocking roots and can protect the waterproof layer. The maximum compressive strength of the concave-convex storage and drainage board is $15 \mathrm{tons} / \mathrm{m}^{2}$, and the planting of general green roofs will not exceed 1.5 tons $/ \mathrm{m}^{2}$, so this concave-convex drainage board can be used for any kind of roof greening.

Reinforced storage and drainage boards not only have the advantages of "storage" and "drainage", but also increase the permeability of the soil, so they are often used in the design of roof gardens. During construction, on the inner side of the planting tank, the water storage and drainage board is placed vertically, and then communicates with the water storage and drainage board at the bottom of the planting soil to form an aeration layer, thereby enhancing the permeability of the soil.

\subsubsection{Biological Concrete}

Biological concrete is a kind of concrete that can be repaired by microorganisms. This concrete benefits from the discovery of a bacterium that can produce limestone, and limestone is an artifact that effectively repairs cracks in concrete. The emergence 
of this new material can improve the cracking of concrete due to pressure. When water penetrates into the concrete through cracks, bacteria will be activated and limestone will be generated. According to the current state of use, biological concrete can heal cracks of up to $0.8 \mathrm{~mm}$ in 3 weeks.

The performance of bio-concrete makes it perfect for use on the roof of a roof garden, because it solves the most difficult waterproof problem in the roof garden. In order to enhance its waterproof effect, it can be used in conjunction with waterproof self-adhesive coils. Not only that, moss and lichen will grow on the building wall mixed with bio-concrete. They absorb carbon dioxide, improve the air quality of the city, and make the building have a certain degree of thermal insulation. At present, scientists are thinking about how to make the plants grow rapidly in bio-concrete, so that the plants in the roof garden show green grass and lush scenery all year round.

\section{THE DEVELOPMENT TREND OF NEW MATERIALS IN CONTEMPORARY LANDSCAPE DESIGN}

\subsection{Summary of the Characteristics of New Materials and Their Application in Garden Landscape}

The position of materials in the landscape is undoubted, and it is especially important to choose the right materials when planning and designing the landscape. When selecting materials, it is necessary to consider not only the location and cultural heritage of the site, but also whether the material can solve the characteristics required by the site. For example, rainy areas in the south need good water-permeable materials, children's play areas need non-slip materials, and roof gardens need materials with strong water storage properties. An environmentally friendly society needs low-carbon and environmentally friendly materials. A resource-conserving society needs materials that save energy and last a long time. Therefore, designers need to understand the excellent characteristics of the materials (Table 3).

Table 3 Characteristics of new materials

\begin{tabular}{cl}
\hline Characteristic type & \multicolumn{1}{c}{ New materials with characteristics } \\
\hline Permeable & Permeable concrete, self-cleaning permeable brick, ecological permeable watercolor stone \\
Light transmission & Translucent concrete \\
Impound & VYDRO foam, reinforced drainage board \\
Waterproof & Fiber optic lighting, bio-concrete \\
Fire prevention & Wood plastic composite \\
Resistant & Weathering steel, wood-plastic composite materials, fiber optic lighting \\
Antiskid & Self-cleaning permeable brick, PC imitation stone brick, ecological permeable watercolor stone \\
Wood-plastic composite materials, laser lighting, solar lighting, VYDRO foam, BSC biological \\
Energy saving and environmental protection \\
matrix concrete \\
Wong lasting
\end{tabular}

The above table summarizes some of the characteristics of the new materials, and also reflects the market's respect for energy-saving and environmentally-friendly materials. There is a greater demand for materials with basic conditions such as non-slip, wear resistance, service life, and corrosion resistance. Materials with new functions, such as light transmission, have certain requirements. It can be seen that most of the materials available in current landscape design are those with basic functions and environmental protection. Materials with new functions are not very common. There are many reasons why such materials have not been generally used. The cost of transparent concrete is too high, which intangibly increases costs. The brightness of fiber optic lighting is not enough, which has certain requirements for the installation environment. The solar lighting will be restricted by natural factors. Glowing Lines luminous paint is currently not stable enough and is easily washed away by rain. If these issues are resolved in the next few years, the landscape materials will be more colorful.

In addition, with the development of the times, people's needs have risen from the functional needs of the material to the emotional needs of the spirit. These mainly focus on the external properties of materials such as physics and chemistry, and do not express the internal emotions of materials, and ignore the spiritual and emotional needs of users. Although a few designers 
have paid attention to this problem and are trying to solve it, the process is relatively slow.

\subsection{Development Trend of New Materials}

The development of materials is the most anticipated in contemporary landscape design, and it is also an indispensable means for designers to express their works. From ancient primitive materials to today's metal, concrete, fiber and other materials, all those things reflect the progress of the times. Nowadays, green city and sponge city are highly respected by the society, which makes designers consider different materials when designing their works. Even in high-rise and densely populated cities, designers strive to achieve the goal of a modern green city. Users can also experience the future development direction of materials.

New materials are low-carbon, environmentally friendly and ecological. Low-carbon environmental protection materials have the characteristics of renewable, low consumption, strong practicability, and low cost. They can achieve environmental protection effects through the recycling of natural resources. Low-carbon environmental protection generally uses industrial production, so the quality is relatively stable and the cost is low. The pollution in the production process is also relatively small. For example, biological concrete, which can repair the cracking condition of concrete, is very practical. Solar lighting uses natural resources to play the role of lighting.

New materials are lightweight and high-strength composite. The new composite material is made of several materials. This gives raw materials new life, such as wood-plastic composite materials, translucent concrete, etc. They are displayed in front of people with a new look, showing colorful visual effects and exerting different effects.

New materials are diversified horizontally. Most of the early landscape designs used natural materials that were sourced locally. The development of materials in the landscape was relatively lagging, and now more and more new materials in municipal, architectural, industrial and other industries are being used in landscape gardens. The appearance and function of materials in the landscape are updated. For example, weathering steel was originally used as a material for building walls, and is now more and more common in landscapes. The imitation stone bricks were originally used as interior materials, and now they are gradually used in landscape paving.

\section{CONCLUSION}

The expectations of some new materials are very high, but some materials are very unstable. Their performance is extremely unstable. It is necessary to continue research and pass the test before they can be widely used in landscape design and application. The industry is not developed, or the production cost is too high, so some materials with new life have been widely used abroad, and they cannot be promoted in China. The lack of variety of materials is a factor restricting the development of domestic landscape design. In addition, landscape architects are the contributors of the spirit of landscape places. Landscape architects must be predictive of the use of landscape materials and have different perceptions of different materials. It is the mission of landscape architects to use new materials in landscape places reasonably, to stimulate viewers to discover unusual aesthetic experiences, and to guide users in their awareness of low-carbon environmental protection.

\section{REFERENCE}

[1] Baugher S. Visible charity: The archaeology, material culture, and landscape design of New York city's municipal almshouse complex, 1736-1797. Int J Hist Archaeology 2001,5(2):175-202.

[2] Herrington S, Studtmann K. Landscape interventions: new directions for the design of children's outdoor play environments. Landsc Urban Plan 1998,42(2-4):191-205.

[3] Ye F, He C, Wang SM, Zhang JL. Landscape design of mountain highway tunnel portals in China. Tunn Undergr Space Technol 2012,29:52-68.

[4] Lin Z H U. Inheritance and Innovation of Culture in Contemporary Architectural Landscape Design. J Anhui Agric Sci 2009,10 .

[5] Ahern J. Urban landscape sustainability and resilience: the promise and challenges of integrating ecology with urban planning and design. Landsc Ecol 2013,28(6):1203-1212. 
[6] Carr AJP. Choctaw Eco-Industrial Park: an ecological approach to industrial land-use planning and design. Landsc Urban Plan 1998,42(2-4):239-257.

[7] Olin L. Form, meaning, and expression in landscape architecture. Landsc J 1988,7(2):149-168.

[8] Tian-yu W. The Use of Building Materials in Landscape. Chin Landsc Archit 2011,8.

[9] Zhang L, Chen F. Landscape Diachrony in the design expression for Meishan Culture Park: A survey. J Asian Archit Build Eng 2014,13(1):157-162.

[10] Gong D, Xie H, Xu XJ, Fu XS, Li HF. A new concept of landscape design in highway construction. Proceedings of the 24th Southern African Transport Conference (SATC 2005) 2005,11:13.

[11] Nassauer JI, Raskin J. Urban vacancy and land use legacies: A frontier for urban ecological research, design, and planning. Landsc Urban Plan 2014,125:245-253.

[12] Egoz S, Bowring J. Beyond the romantic and naive: the search for a complex ecological aesthetic design language for landscape architecture in New Zealand. Landsc Res 2004,29(1):57-73.

[13] Rackham S. Beyond Landscape MacArchitecture: new languages, new landscapes. Landsc Rev 1996,2(3):33-44.

[14] Gazvoda D. Characteristics of modern landscape architecture and its education. Landsc Urban Plan 2002,60(2):117-133.

[15] Ignatieva M, Stewart G H. Homogeneity of urban biotopes and similarity of landscape design language in former colonial cities. Cambridge University Press 2009.

[16] Hansen G. Landscape Design: Ten Important Things to Consider. EDIS 2009,2009(2). 